\title{
Evaluation of microalbuminuria in patients with hypertension from North Indian population: A case-control study
}

\author{
Roshan Alam ${ }^{1}$, Mohd Arif ${ }^{2}$, Saba Khan ${ }^{3, *}$, Mohammad Mustufa Khan ${ }^{4}$ \\ ${ }^{1}$ Professor \& HOD, ${ }^{2}$ PG Student, ${ }^{3}$ Assistant Professor, ${ }^{4}$ Research Scholar, Dept. of Biochemistry, Integral Institute of Medical \\ Sciences \& Research, Integral University, Lucknow, Uttar Pradesh, India
}

*Corresponding Author:

Email: dr.khan.saba@gmail.com

Received: $08^{\text {th }}$ November, 2017

Accepted: $12^{\text {th }}$ February, 2018

\begin{abstract}
Introduction: Microalbuminuria has recently emerged as an early marker of hypertension induced target organ damage. Microalbuminuria in hypertensive patients may act as a potential risk factor for cardiovascular and kidney diseases.

Objective: The aim of the study is to evaluate the levels of microalbuminuria in hypertensive (HT) patients and normotensive (NT) control subjects.

Materials and Methods: In this case-control study, 42 HT patients and 42 age and gender matched NT controls were enrolled. Body mass index (BMI), systolic and diastolic blood pressure (SBP and DBP) was measured by standard protocol. Urinary microalbumin and creatinine were estimated in spot urine sample of all subjects using commercially available kit. Chi-square test, unpaired $t$ test and Pearson correlation coefficient were used for Statistical analysis. The p-value $<0.05$ was considered statistically significant.

Results: In this study, results showed that more than half of the HT patients have smoking habits (59.3\%), alcoholic habits (71.4\%) and family history of HT (73.8\%), which is significantly higher as compared to NT controls $(\mathrm{p}=0.02, \mathrm{p}=0.004, \mathrm{p}=0.02$, respectively). Anthropometric parameters height, weight and BMI were found significantly higher in HT patients as compared to NT controls ( $\mathrm{p}=0.01, \mathrm{p}=0.007, \mathrm{p}=0.001$, respectively). Mean of SBP and DBP were also found significantly higher in HT patients than NT controls $(\mathrm{p}=0.001, \mathrm{p}=0.001$, respectively). Urinary microalbumin, urinary creatinine and albumin creatinine ratio (ACR) were found significantly higher in HT patients as compared to NT controls $(\mathrm{p}=0.02, \mathrm{p}=0.01, \mathrm{p}=0.02$, respectively). Correlation of various anthropometric and clinical parameters showed that ACR have significantly positive correlation with age in HT patients $(\mathrm{r}=0.364, \mathrm{p}<0.05)$. Although, Urinary creatinine levels have negative correlation with age in HT patients, but not significant $(\mathrm{r}=-$ 0.027). Similarly, ACR also have negative correlation with BMI, SBP and DBP in HT patients $(r=-0.068, r=-0.145, r=-0.219$, respectively), but these are not significant.

Conclusions: Interestingly, more than half of the hypertensive cases have family history of HT in this study population. Urinary microalbumin, urinary creatinine and ACR were found significantly higher in HT patients than NT controls. ACR has significantly positive correlation with age in HT patients.
\end{abstract}

Keywords: Hypertension, Normotension, Microalbuminuria, Urinary creatinine, Albumin-creatinine ratio, Body mass index.

\section{Introduction}

Hypertension is one of the most challenging health problems in the world. It has been estimated that, globally, almost one billion individuals have hypertension. ${ }^{1}$ By 2025 , that number is estimated to increase by $60 \%$, which means that 1.56 billion people could be hypertensive. ${ }^{2}$ WHO statistics report showed that hypertension is the leading cause of mortality worldwide and responsible for $13 \%$ of global deaths. ${ }^{3}$

Several studies reported that the prevalence of microalbuminuria in hypertensive subjects ranges from $4.7 \%$ to $58.4 \%{ }^{4,5}$ In another hand, the prevalence of microalbuminuria in different populations with the same clinical condition varies significantly. The prevalence of microalbuminuria in British population is about $11.8 \%,{ }^{6}$ US population $7.1 \%$ to $8.2 \%{ }^{7}$ and Asian populations $31 \% .^{8}$ A comparison between South Asian and white European populations living in the UK revealed that microalbuminuria is significantly more common in Asians (31\% versus 20\%). ${ }^{8}$ Prevalence of microalbuminuria was $6.6 \%$ in non-diabetic, non- hypertensive individuals. Similarly, $6.2 \%$ prevalence of microalbuminuria was reported by the Kidney Evaluation and Awareness Program in Sheffield (KEAPS). ${ }^{9}$

Microalbuminuria has recently emerged as an early marker of hypertension induced target organ damage. A large number of studies all over the world have found a strong correlation between onset of microalbuminuria and biochemical markers of atherosclerosis (high LDL, TG and reduced HDL) and have found a strong association between microalbuminuria and severity and duration of hypertension; micro vascular changes in kidneys, retina, and heart. ${ }^{10}$

Microalbuminuria has been associated with a number of unfavourable bio humoral risk factor as well as with subclinical organ damage in non diabetic patients with primary hypertension. Microalbuminuria reported in $10-40 \%$ of non- diabetics with hypertension, may serve as an early indicator of risk to develop subsequent proteinuria and progressive renal impairment. ${ }^{11}$ Until late in the course of hypertensive nephropathy, renal damage is asymptomatic and 
laboratory findings are subtle. The first objective sign of renal involvement is a small increase in the amount of albumin in urine. The normal range for urinary ACR is less than $30 \mathrm{mg} / \mathrm{gm}$; ACR in the range of 30 $300 \mathrm{mg} / \mathrm{gm}$, which can be missed with routine clinical laboratory methods (e.g. Dipstick) is referred to as "Microalbuminuria"."11

The Joint National Commission on Hypertension (JNC VII) report includes microalbuminuria as evidence for the presence of target organ damage. Target Organ Damage indicates the need for more aggressive control of blood pressure (BP). However, routine evaluation of microalbuminuria is not recommended by international guidelines as part of the diagnostic workup of every hypertensive patient. ${ }^{12} \mathrm{Klag}$ et al. had reported that essential hypertension strongly associated with end-stage renal disease (ESRD) in the African-American, ${ }^{13}$ whether such finding can be extended to other population (e.g. Caucasian cohort) is still unclear.

The aim of our study was to detect microalbuminuria in essential hypertension and its relation to severity of hypertension, BMI, age and potential risk factors for target organ damage such as hypertensive nephropathy in north Indian population.

\section{Materials and Methods}

Subject Selection: This case-control study was approved by the institutional ethical committee of the University. Subjects with HT patients and NT controls were enrolled from the outpatients attending the Out Patients Department of Medicine, IIMS\&R, Integral University, Lucknow aged between 18 to 70 years based on inclusion/exclusion criteria. Written informed consent was taken from each subject and all procedures performed in studies involving human participants were in accordance with the ethical standards of this university and with the 1964 Helsinki declaration and its later amendments or comparable ethical standards.

The selected subjects have given their medical history, their family history, personal information and also undergone relevant investigations. Hypertensive patients were selected as per the Joint National Committee-7th definition of high blood pressure. ${ }^{14}$

\section{Anthropometric parameters}

Blood pressure measurement: After resting for 10 minutes in a sitting position, SBP and DBP were measured twice by the same two investigators using the same manual sphygmomanometer for all subjects. Mean blood pressures of two measurements were recorded.

BMI Estimation: Weight was recorded to the nearest kilogram $(\mathrm{kg})$ with the subject standing on the weighing machine without shoes and using minimum of clothing. The same weighing machine was used for all the study subjects and the machine was tested with a known set of weights for any error. ${ }^{[15]}$ Height was recorded with the subject erect; bare footed; feet together; back and heels against the upright bar of height scale; head upright in Frankfort horizontal plane "look straight ahead".${ }^{\text {ec }}$

Body Mass index was calculated from the formula; [BMI = Weight in Kilogram/ (Height in meters $)^{2}$ ]

Laboratory investigations: $5 \mathrm{ml}$ urine sample is collected in to sterile container on the same day and estimated for urinary microalbumin and creatinine. Laboratory standard operation procedures are maintained for all laboratory analysis. Urinary microalbumin and creatinine were investigated in all subjects by using commercially available kit on Siemens' RXL fully chemistry Auto-analyzer.

\section{Statistical Analysis}

All the analysis was carried out by using SPSS 16.0 version (Chicago, Inc., USA). The results are presented in mean $\pm \mathrm{SD}$ and percentage. Chi-square test is used to compare the categorical variables between cases and controls. Unpaired t-test is used to compare the study parameters between cases and controls. The Pearson correlation coefficient was calculated among the study parameters. The $\mathrm{p}$-value $<0.05$ was considered significant.

\section{Results}

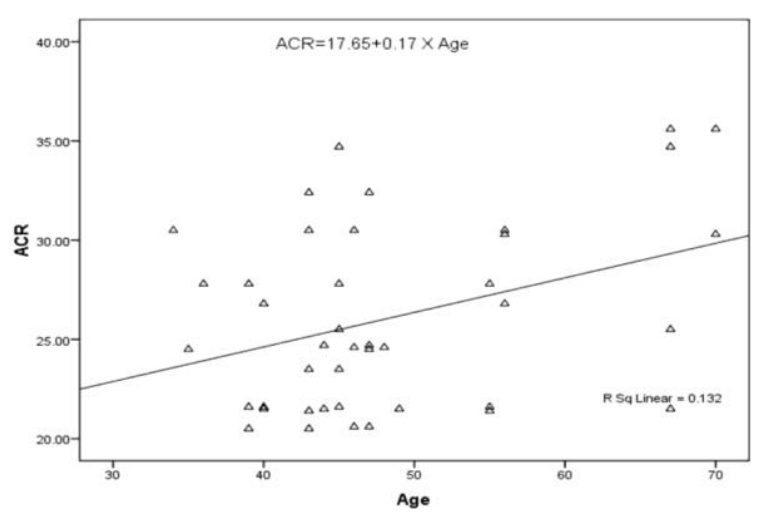

Fig. 1: Scatter diagram showing correlation between age and ACR among HT cases 
Table 1: Demographical characteristics of HT cases and NT control groups

\begin{tabular}{|c|c|c|c|c|}
\hline \multicolumn{2}{|c|}{ Parameters } & $\underset{(n=42)}{H T}$ & $\begin{array}{c}\text { NT } \\
(n=42)\end{array}$ & P-value \\
\hline \multirow{2}{*}{ Age (years) } & $<40$ & $7(16.7)$ & $5(11.9)$ & \multirow{2}{*}{0.76} \\
\hline & $\geq 40$ & $35(83.3)$ & $37(88.1)$ & \\
\hline \multirow{2}{*}{ Gender } & Male & $25(59.5)$ & $26(61.9)$ & \multirow{2}{*}{1.00} \\
\hline & Female & $17(40.5)$ & $16(38.1)$ & \\
\hline \multirow{2}{*}{$\begin{array}{l}\text { Smoking } \\
\text { habit }\end{array}$} & Present & $25(59.5)$ & $14(33.3)$ & \multirow{2}{*}{$0.02 *$} \\
\hline & Absent & $17(40.5)$ & $28(66.7)$ & \\
\hline \multirow{2}{*}{$\begin{array}{l}\text { Alcoholic } \\
\text { habit }\end{array}$} & Present & $30(71.4)$ & $16(38.1)$ & \multirow{2}{*}{$0.004 *$} \\
\hline & Absent & $12(28.6)$ & 26 (61.9) & \\
\hline \multirow{2}{*}{$\begin{array}{l}\text { Family } \\
\text { history of HT }\end{array}$} & Present & $31(73.8)$ & $20(47.6)$ & \multirow{2}{*}{$0.02 *$} \\
\hline & Absent & $11(26.2)$ & $22(53.4)$ & \\
\hline
\end{tabular}

Values are expressed as Number (Percentage)

*Significant considered as $\mathrm{P}<0.05$.

HT: Hypertensive, NT: Normotensive

Table 2: Anthropometric and clinical parameters of HT cases and NT control groups

\begin{tabular}{|l|c|c|c|}
\hline \multicolumn{1}{|c|}{ Parameters } & HT $(\mathbf{n}=\mathbf{4 2})$ & $\mathbf{N T}(\mathbf{n}=\mathbf{4 2})$ & P-value \\
\hline Age $($ years $)$ & $48.43 \pm 9.76$ & $51.02 \pm 9.90$ & 0.83 \\
\hline Height $(\mathrm{cm})$ & $155.86 \pm 6.21$ & $158.83 \pm 4.54$ & $0.01^{*}$ \\
\hline Weight $(\mathrm{kg})$ & $60.40 \pm 8.34$ & $56.05 \pm 5.82$ & $0.007^{*}$ \\
\hline BMI $\left(\mathrm{kg} / \mathrm{m}^{2}\right)$ & $24.92 \pm 3.62$ & $22.25 \pm 2.52$ & $0.0001^{*}$ \\
\hline SBP $(\mathrm{mmHg})$ & $147.62 \pm 6.46$ & $112.26 \pm 2.09$ & $0.0001^{*}$ \\
\hline DBP $(\mathrm{mmHg})$ & $87.21 \pm 7.82$ & $68.88 \pm 4.16$ & $0.0001^{*}$ \\
\hline $\begin{array}{l}\text { Urinary micro } \\
\text { albumin level } \\
(\mathrm{mg} / \mathrm{mmol})\end{array}$ & $26.09 \pm 4.66$ & $24.03 \pm 3.50$ & $0.02^{*}$ \\
\hline $\begin{array}{l}\text { Urinary } \\
\text { creatinine level } \\
(\mathrm{mg} / \mathrm{dl})\end{array}$ & $1.26 \pm 0.26$ & $1.10 \pm 0.26$ & $0.01^{*}$ \\
\hline ACR $(\mathrm{mg} / \mathrm{dl})$ & $26.09 \pm 4.66$ & $24.03 \pm 3.50$ & $0.02^{*}$ \\
\hline
\end{tabular}

Values are expressed as Mean \pm Standard Deviation

*Significant considered as $\mathrm{P}<0.05$.

HT: Hypertensive, NT: Normotensive, BMI: Body Mass Index, SBP: Systolic Blood Pressure, DBP: Diastolic Blood Pressure, ACR: Albumin Creatinine Ratio

Table 3: Correlation of anthropometric and clinical parameters in HT cases

\begin{tabular}{|l|c|c|c|c|c|c|c|c|}
\hline Parameters $\rightarrow \downarrow$ & Age & Height & Weight & BMI & SBP & DBP & ACR & $\begin{array}{c}\text { Urinary } \\
\text { creatinine }\end{array}$ \\
\hline Age & 1 & -0.182 & -0.029 & 0.068 & 0.135 & -0.018 & $0.364^{*}$ & -0.027 \\
\hline Height & - & 1 & 0.202 & $-0.341^{*}$ & -0.005 & 0.061 & 0.130 & 0.272 \\
\hline Weight & - & - & 1 & $0.850^{* *}$ & 0.280 & 0.129 & 0.014 & 0.020 \\
\hline BMI & - & - & - & 1 & 0.281 & 0.090 & -0.068 & -0.126 \\
\hline SBP & - & - & - & - & 1 & $0.656^{* *}$ & -0.145 & -0.174 \\
\hline DBP & - & - & - & - & - & 1 & -0.219 & 0.011 \\
\hline ACR & - & - & - & - & - & - & 1 & -0.078 \\
\hline $\begin{array}{l}\text { Urinary } \\
\text { creatinine }\end{array}$ & - & - & - & - & - & - & - & 1 \\
\hline
\end{tabular}

*Correlation is significant at the 0.05 level (2-tailed)

$* *$ Correlation is significant at the 0.01 level (2-tailed)

HT: Hypertensive, BMI: Body Mass Index, SBP: Systolic Blood Pressure, DBP: Diastolic Blood Pressure, ACR: Albumin Creatinine Ratio 
In this case-control study, 42 HT patients and 42 age and gender matched NT controls were enrolled. Out of this, 59.3\% HT patients have smoking habits, which is significantly differed from NT controls $(\mathrm{p}=0.02)$. Similarly, $71.4 \%$ HT patients have alcoholic habits, which is also significantly differed from NT controls ( $\mathrm{p}=0.004$ ). In addition, 73.8\% HT patients have family history of HT, which is found significantly higher than NT controls $(\mathrm{p}=0.02)$ shown in Table 1.

Table 2 shows that the mean age of HT patients (48.43 \pm 9.76 years) and NT controls (51.02 \pm 9.90 years) in this study. Anthropometric parameters height, weight and BMI were found significantly higher in HT patients as compared to NT controls ( $\mathrm{p}=0.01, \mathrm{p}=0.007, \mathrm{p}=0.001$, respectively). Mean of SBP and DBP were also found significantly higher in HT patients than NT controls $(\mathrm{p}=0.001, \quad \mathrm{p}=0.001, \quad$ respectively). Urinary microalbumin, urinary creatinine and ACR were found significantly higher in HT patients as compared to NT controls ( $\mathrm{p}=0.02, \mathrm{p}=0.01, \mathrm{p}=0.02$, respectively).

Correlation of various anthropometric and clinical parameters showed that ACR have significantly positive correlation with age in HT patients $(r=0.364$, $\mathrm{p}<0.05)$. Although, Urinary creatinine levels have negative correlation with age in HT patients, but not significant $(\mathrm{r}=-0.027)$. ACR also have negative correlation with BMI, SBP and DBP in HT patients ( $\mathrm{r}=$ $-0.068, \mathrm{r}=-0.145, \mathrm{r}=-0.219$, respectively), but these are not significant (Table 3).

\section{Discussion}

In this study, results showed that more than half of the HT patients have smoking habits (59.3\%), alcoholic habits $(71.4 \%)$ and family history of HT (73.8\%), which is significantly higher as compared to NT controls. Several studies previously reported with accordance of our findings. ${ }^{17-19}$

Virdis et al. reported that hypertensive patients with smoking habits are more likely to develop severe hypertension, which including malignant and renovascular hypertension, an effect likely due to an accelerated atherosclerosis. ${ }^{17}$ Findings identify an increase in BP of active smokers or non-smokers exposed to passive smoking, while a lot of others refer a lowering of BP due to smoking. This discrepancy could be explained as follows. In initial phase of smoking, a vasoconstriction mediated by nicotine causes acute but transient elevation in SBP. This phase is followed by a decrease in $\mathrm{BP}$ as a consequence of depressant effects played chronically by nicotine itself. Concurrently, carbonmonoxide is acting directly on the arterial wall and causing structurally irreversible alterations in the long time exposure. At this time, there is a change in BP that increases again, and often constantly, its levels following chronic exposure. In HT patients with smoking habits, it has been observed that response of antihypertensive drugs altered, because smoking influences metabolic steps of the drugs. ${ }^{20}$

Puddey et al. previously had reported that alcohol consumption may play a major role in the elevation of BP in NT controls also, which can be reversed when normal drinking habits were resumed. ${ }^{21}$ Arkwright et al. had reported that alcohol consumption was largely responsible for the 3-4 folds excess of hypertension in moderate to heavy drinkers. ${ }^{22}$ In a recent study, Roerecke et al. suggested that a reduction of alcohol intake reduces BP in a dose-dependent manner and implementation of effective alcohol interventions would substantially reduce the disease burden from both alcohol and raised BP. ${ }^{18}$

An increase in the number of family members with hypertension was associated with an increasing prevalence of hypertension and BP in the probands, independent of conventional risk factors for hypertension. Family members of hypertensive subjects may need to be treated in primary prevention efforts related to hypertension. ${ }^{23}$ Ranasinghe et al. showed that the prevalence of hypertension was significantly higher in those with a family history (FH) of hypertension. FH of hypertension was also associated with the prevalence of obesity, central obesity and metabolic syndrome. Individuals who have FH of hypertension can be easily identified and benefitted from targeted interventions. ${ }^{19}$

Results showed that anthropometric parameters height, weight and BMI were found significantly higher in HT patients as compared to NT controls. Yu et al. reported that increased BMI was an increased risk for hypertension in Chinese adult population. ${ }^{24}$ In an epidemiological study, Bovet et al. observed that prevalence of high BP was elevated with excess body weight in the urban population in an early stage of the epidemiological transition of a country. ${ }^{25}$

Mean of SBP and DBP were also found significantly higher in HT patients than NT controls in our study. This indicates that the HT patients needed drug intervention to reduce the progression and development of cardiovascular diseases (CVD) with increasing age. A Joint National Committee on Prevention, Detection, Evaluation, and Treatment of High Blood Pressure provided key messages that those older than age 50, SBP of $>140 \mathrm{mmHg}$ is a more important CVD risk factor than DBP; beginning at $115 / 75 \mathrm{mmHg}$, CVD risk doubles for each increment of $20 / 10 \mathrm{mmHg}$; those who are normotensive at 55 years of age will have a 90 percent lifetime risk of developing hypertension; prehypertensive individuals (SBP 120$139 \mathrm{mmHg}$ or DBP $80-89 \mathrm{mmHg}$. ${ }^{14}$

Urinary microalbumin, Urinary creatinine and ACR were found significantly higher in HT patients as compared to NT controls in our study population. Gupta et al. studied that the microalbuminuria positive cases had significantly higher SBP. Microalbuminuria positive HT patients had significantly higher level of serum creatinine, because microalbuminuria positive 
HT patients had significantly lower creatinine clearance and a higher uric acid and cholesterol, which are leading cause of coronary artery disease and retinopathy in microalbuminuria positive HT patients. ${ }^{10}$

Correlation of various anthropometric and clinical parameters showed that ACR have significantly positive correlation with age in HT patients. Although, ACR have negative correlation with BMI, SBP and DBP in HT patients, but these are not significant. Higher ACRs, even within the normal range, are independently associated with increased risk for development of hypertension among women without diabetes. ${ }^{26}$ Sung et al. observed that low levels of ACR (below $30 \mathrm{mg} / \mathrm{g}$ ) and albuminuria are linked with increased risk of hypertension and CVD mortality at follow-up, but are not associated with increased risk of diabetes mellitus. ${ }^{27} \mathrm{~A}$ multiple regression analysis showed that age was an independent predictor of spot ACR. ${ }^{28}$ Similarly, the ACR distribution exhibited a highly skewed pattern, with approximately $60 \%$ of untreated, non-diabetic hypertensive patients exhibiting a high-normal or larger ACR. Both hypertension and age are independent risk factors that increase the ACR. The present study indicated that a significant percentage of HT patients require anti-hypertensive drugs with antiproteinuric effects at the start of treatment. ${ }^{29}$

\section{Conclusion}

Interestingly, more than half of the hypertensive cases have family history of HT in this study population. Urinary microalbumin, urinary creatinine and ACR were found significantly higher in HT patients than NT controls. ACR has significantly positive correlation with age in HT patients.

\section{Financial or other competing interests: None}

\section{Acknowledgments}

We are grateful to Dr. Arvind Kumar, Assistant Professor, Department of Medicine, IIMS\&R, Integral University, Lucknow, India for their timely support, advice and critical appraisal of the research work. We also acknowledge to Honorable Professor S. W. Akhtar, Founder, Integral University, Lucknow, India for the invaluable help and instrumentation facility to carry out research work without any hindrance.

\section{References}

1. World Health Organization. Integrated Management of Cardiovascular Risk. Report of a WHO meeting. Geneva, World Health Organization. 2002.
2. Kearney PM, Whelton M, Reynolds K, Muntner P, Whelton PK, He J. Global burden of hypertension: analysis of worldwide data. Lancet. 2005;365(9455):21723.

3. World Health Organization. World Health Statistics, 2012. Geneva, World Health Organization, 2012.

4. Jensen J, Feldt-Rasmussen B, Borch-Johnsen K, Clausen P, Appleyard M, Jensen G. Micro albuminuria and its relation to cardiovascular disease and risk factors. A population-based study of 1254 hypertensive individuals. J Hum Hypertens. 1997;11:727-32.

5. Böhm M, Thoenes M, Danchin N, Bramlage P, Puerta PL, Volpe M. Association of cardiovascular risk factors with micro albuminuria in hypertensive individuals: the iSEARCH global study. J Hypertens. 2007;25:2317-24.

6. Yuyun M, Khaw K, Luben R, Welch A, Bingham S, Day $\mathrm{N}$, Wareham N. Micro albuminuria, cardiovascular risk factors and cardiovascular morbidity in a British population: the EPIC-Norfolk Population-based Study. Eur J Cardiovasc Prev Rehabil. 2004;11:207-13.

7. Coresh J, Selvin E, Stevens L, Manzi J, Kusek J, Eggers P, Van Lente F, Levey A. Prevalence of chronic kidney disease in the United States. JAMA. 2007;298:2038-47.

8. Dixon A, Raymond N, Mughal S, Rahim A, O'Hare JP, Kumar S, Barnett A. Prevalence of micro albuminuria and hypertension in South Asians and white Europeans with type 2 diabetes: a report from the United Kingdom Asian Diabetes Study (UKADS). Diab Vasc Dis Res. 2006;3:22-5

9. Bello A, Peters J, Wight J, El Nahas M. The Kidney Evaluation and Awareness Program in Sheffield (KEAPS): a community-based screening for micro albuminuria in a British population. Nephron Clin Pract. 2010;116:c95-c103.

10. Gupta A, Pal A, Nelson SS. Study of Microalbuminuria in Hypertension. International Journal of Scientific Study. 2015;3(2):32-9.

11. Hoegholm A, Bang LE, Kristensen KS, Neilsen JW, Holm J. Micro albuminuria in 411 untreated individuals with established hypertension, white coat hypertension, and normotension. Hypertension. 1994;24(1):101-5.

12. Leoncini G, Sacchi G, Ravera M et al. Microalbuminuria is an integrated marker of subclinical organ damage in primary hypertension. J. of Human Hypertension. 2002;16:399-404.

13. Klag M, Whelton P, Randall B, Neaton J, Brancati F, Stamler J. End-stage renal disease in African-American and white men. JAMA. 1997;277:1293-8.

14. Lenfant C, Chobanian AV, Jones DW, Roccella EJ. Seventh report of the Joint National Committee on the Prevention, Detection, Evaluation, and Treatment of High Blood Pressure (JNC 7): Resetting the hypertension sails. Hypertension. 2003;41:1178-9.

15. Verma BL, Kumar A, Srivastava RN. Measurement of body build based on weight/height, an index for adults in an Indian population. Ind J Pub Health. 1982;26:133-43.

16. Frisancho AR. New standards of weight and body composition by frame size and height for assessment of nutritional status in adults and elderly. Amm J Clin Nutr. 1984;40:808-19.

17. Virdis A, Giannarelli C, Neves MF, Taddei S, Ghiadoni L. Cigarette smoking and hypertension. Curr Pharm Des. 2010;16(23):2518-25.

18. Roerecke M, Kaczorowski J, Tobe SW, Gmel G, Hasan OSM, Rehm J. The eff ect of a reduction in alcohol consumption on blood pressure: a systematic review and meta-analysis. Lancet Public Health. 2017;2:e108-20. 
19. Ranasinghe P, Cooray DN, Jayawardena R, Katulanda P. The influence of family history of hypertension on disease prevalence and associated metabolic risk factors among Sri Lankan adults. BMC Public Health. 2015; 15:576.

20. Leone A. Does Smoking Act as a Friend or Enemy of Blood Pressure? Let Release Pandora's Box. Cardiology Research and Practice. Volume 2011; Article ID 264894:7.

21. Puddey IB, Beilin LJ, Vandongen R, Rouse IL, Rogers P. Evidence for a direct effect of alcohol consumption on blood pressure in normotensive men: a randomized controlled trial. Hypertension. 1985;7:707-13.

22. Arkwright PD, Beilin LJ, Rouse I, Armstrong BK, Vandongen R. Effects of alcohol use and other aspects of lifestyle on blood pressure levels and prevalence of hypertension in a working population. Circulation. 1982;66:60-6.

23. Tozawa M, Oshiro S, Iseki C, Sesoko S, Higashiuesato Y, Tana T, Ikemiya Y, Iseki K, Fukiyama K. Family history of hypertension and blood pressure in a screened cohort. Hypertens Res. 2001;24(2):93-8.

24. Yu J, Zou D, Xie MT, Ye Y, Zheng T, Zhou S, Huang L, Liu X, Xun J, Zhou Y. The interaction effects of risk factors for hypertension in adults: a cross-sectional survey in Guilin, China. BMC Cardiovascular Disorders. 2016;16:183.

25. Bovet P, Ross AG, Gervasoni JP, Mkamb M, Mtasiwa DM, Lengeler C, Whiting D, Paccaud F. Distribution of blood pressure, body mass index and smoking habits in the urban population of Dar es Salaam, Tanzania, and associations with socioeconomic status. International Journal of Epidemiology. 2002;31:240-7.

26. Forman JP, Fisher NDL, Schopick EL, Curhan GC. Higher Levels of Albuminuria within the Normal Range Predict Incident Hypertension. J Am Soc Nephrol. 2008;19(10):1983-8.

27. Sung KC, MD, Ryu S, Lee JY, Lee SH, Cheong ES, Hyun YY, Lee KB, Kim H, Byrne CD. Urine Albumin/Creatinine Ratio below $30 \mathrm{mg} / \mathrm{g}$ is a Predictor of Incident Hypertension and Cardiovascular Mortality. J Am Heart Assoc. 2016;5:e003245.

28. Houlihan CA, Tsalamandris C, Akdeniz A, Jerums G. Albumin to creatinine ratio: a screening test with limitations. Am J Kidney Dis. 2002;39(6):1183-9.

29. Ohmaru N, Nakatsu T, Izumi R, Mashima K, Toki M, Kobayashi A, Ogawa H, Hirohata S, Ikeda S, Kusachi S. Distribution pattern of urine albumin creatinine ratio and the prevalence of high-normal levels in untreated asymptomatic non-diabetic hypertensive patients. Intern Med. 2011;50(16):1621-9. 